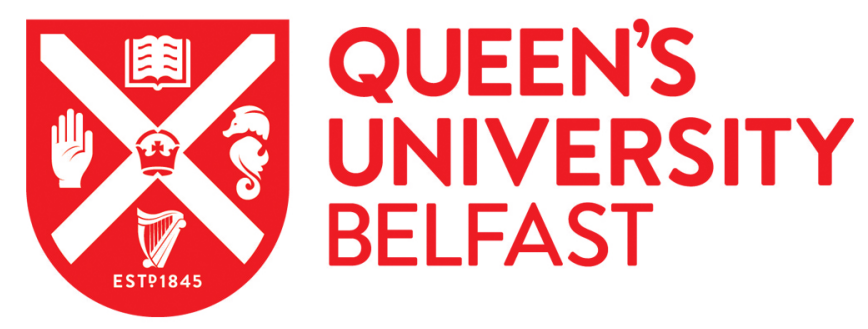

\title{
Using Pedometer Step-Count Goals to Promote Physical Activity in Cardiac Rehabilitation: A Feasibility Study of a Controlled Trial
}

\author{
Cupples, M., Dean, A., Tully, M. A., Taggart, M., McCorkell, G., O’Neill, S., \& Coates, V. (2013). Using \\ Pedometer Step-Count Goals to Promote Physical Activity in Cardiac Rehabilitation: A Feasibility Study of a \\ Controlled Trial. International Journal of Physical Medicine and Rehabilitation, 1(7), [157]. \\ https://doi.org/10.4172/2329-9096.1000157
}

Published in:

International Journal of Physical Medicine and Rehabilitation

Document Version:

Publisher's PDF, also known as Version of record

Queen's University Belfast - Research Portal:

Link to publication record in Queen's University Belfast Research Portal

\section{Publisher rights}

Copyright 2013 the authors.

This is an open access article published under a Creative Commons Attribution License (https://creativecommons.org/licenses/by/4.0/), which permits unrestricted use, distribution and reproduction in any medium, provided the author and source are cited.

\section{General rights}

Copyright for the publications made accessible via the Queen's University Belfast Research Portal is retained by the author(s) and / or other copyright owners and it is a condition of accessing these publications that users recognise and abide by the legal requirements associated with these rights.

Take down policy

The Research Portal is Queen's institutional repository that provides access to Queen's research output. Every effort has been made to ensure that content in the Research Portal does not infringe any person's rights, or applicable UK laws. If you discover content in the Research Portal that you believe breaches copyright or violates any law, please contact openaccess@qub.ac.uk. 


\title{
Using Pedometer Step-Count Goals to Promote Physical Activity in Cardiac Rehabilitation: A Feasibility Study of a Controlled Trial
}

\section{Margaret Cupples ${ }^{1,2}$, Annette Dean ${ }^{3}$, Mark A Tully, ${ }^{1,2}$, Margaret Taggart ${ }^{3}$, Gillian McCorkell ${ }^{3}$, Siobhan O'Neill' and Vivien Coates ${ }^{3,5}$}

${ }^{1}$ Department of General Practice and Primary Care, Queen's University, Belfast, UK

${ }^{2}$ UKCRC Centre of Excellence for Public Health Research (NI), Queen's University, Belfast, UK

${ }^{3}$ Western Health and Social Care Trust, Northern Ireland

${ }^{4}$ Psychology Research Institute, University of Ulster, Belfast, UK

${ }^{5}$ University of Ulster, Belfast, UK

\begin{abstract}
Background: There is a need to improve the effectiveness of strategies to help cardiac rehabilitation patients achieve recommended levels of physical activity; the use of pedometers requires further research. We aimed to examine the feasibility of a randomised controlled trial, of an intervention using pedometer step-count goals, to promote physical activity for cardiac rehabilitation patients.
\end{abstract}

Methods: We invited patients who completed a supervised cardiac rehabilitation programme to participate in this community-based study. Consenting participants wore a Yamax CW-701 pedometer for one week, blinded to stepcount readings, before being randomly allocated to groups. Intervention groups were told their step-counts; working with a clinical facilitator (nurse or physiotherapist) individually, they set daily step-count goals and reviewed these weekly. Baseline step-counts were hidden from controls, who were not given pedometers but received ongoing weekly facilitator support. After six weeks both groups wore 'blinded' pedometers for outcome assessment and participated in semi-structured interviews which explored their experiences of the study. Outcomes included rates of uptake, adherence and completion of measures, including step-counts, quality of life (EQ-5D) and stage of behaviour change.

Results: Four programme groups were recruited; two received the intervention. Of 68 invitees, 45 participated $(66 \%)$ (19 intervention; 26 control). Forty-two (93\%) completed the outcomes. Baseline characteristics were comparable between groups. Mean steps/day increased more for intervention participants $(2,742 ; 95 \% \mathrm{Cl} 1,169$ to 4,315$)$ than controls $(-42 ; 95 \% \mathrm{Cl}-1,102$ to 1,017$)(\mathrm{p}=0.004)$. The intervention and on-going clinical contact were welcomed; participants considered that step-counts, compared to time-related targets, encouraged them to become more active.

Conclusion: These findings suggest that an intervention using individually tailored step-count goals may help increase and sustain physical activity following a cardiac rehabilitation programme. A definitive randomised controlled trial using blinded outcome measurements is feasible and of potential value in determining how best to translate physical activity advice into practice.

Keywords: Cardiac rehabilitation; Physical activity; Goal setting; Pedometer; Randomised controlled trial; Feasibility

\section{Introduction}

Physical inactivity is an important contributor to the burden of many non-communicable diseases, including coronary heart disease (CHD) [1]. Increasing physical activity can contribute to reducing the risk of morbidity [2]. However, many patients do not achieve sufficient levels of physical activity (PA) for health benefits and, even after engaging in cardiac rehabilitation (CR), of which PA is a core component, maintenance of PA is poor [3].

Recent reviews indicate that interventions which emphasise selfmonitoring, goal setting, identification of barriers to change and consideration of relapse prevention are most likely to yield positive outcomes for patients $[3,4]$. The use of pedometers in self-monitoring has been reported to be associated with increased levels of PA among cardiac patients [5-8] but information about how pedometers are actually used in goal setting and self-monitoring is scant. More detail would facilitate the translation of previous findings into clinical practice. Most studies of interventions which aim to increase participation in PA appear to set goals based on time spent being physically active; there are few reports to indicate how measurements of step-counts are used. However, a systematic review has highlighted the importance of step-goals in predicting increases in PA [9]. A cadence of 100 steps per minute is considered to represent moderate-intensity activity and, based on this estimation, the recommended 30 minutes of moderate physical activity on most days per week [2] approximates to a goal of taking 3,000 steps in 30 minutes [10].
There has been a call for future studies using rigorous designs and reliable measures, to improve understanding of PA behaviour change after CR [3], in order to inform strategies to increase and sustain patients' levels of PA. Also, a need has been identified for further research using pedometers, to determine ways to improve the effectiveness of current strategies to promote PA [11].

This study aimed to explore the feasibility of a randomised controlled trial, in the context of real-world clinical practice, to determine the effectiveness of a tailored intervention using pedometer step-counts in goal setting for patients following a supervised programme of CR.

\section{Method}

We used a cluster randomised controlled trial design. Four

*Corresponding author: Margaret E Cupples, Department of General Practice and Primary Care, Queen's University, Belfast, UK, Tel: 0044 2890204252; Fax: 0044 2890310202; E-mail: m.cupples@qub.ac.uk

Received July 31, 2013; Accepted September 05, 2013; Published September 10,2013

Citation: Cupples M, Dean A, Tully MA, Taggart M, McCorkell G, et al. (2013) Using Pedometer Step-Count Goals to Promote Physical Activity in Cardiac Rehabilitation: A Feasibility Study of a Controlled Trial. Int J Phys Med Rehabil 1 : 157. doi:10.4172/2329-9096.1000157

Copyright: (c) 2013 Cupples M, et al. This is an open-access article distributed under the terms of the Creative Commons Attribution License, which permits unrestricted use, distribution, and reproduction in any medium, provided the original author and source are credited. 
consecutive groups of patients, who were completing a supervised eight-week, hospital-based out-patient CR programme, were invited by clinical staff to participate in this six-week community-based study. Prior to their CR programme, they had been assessed and risk stratified by clinical staff following the British Association for Cardiovascular Prevention and Rehabilitation (BACPR) guidelines [12]. No programme participant was excluded from invitation. The Office for Research Ethics Committees (Northern Ireland) approved the study (REC Ref- 09/NIR/40). The study took place in the Western Health and Social Care Trust, Northern Ireland. All participants gave written informed consent.

Following completion of their CR programme patients who consented were shown how to wear a validated pedometer (YAMAX Digiwalker CW-701) (Yamax Inc, Japan) and asked to wear it during waking hours, except for water-based activities, for one week. It was taped shut, obscuring step-count records, to provide a 'blinded' baseline measurement. In accordance with advice given during their CR programme, participants were encouraged to aim to achieve 30 minutes of moderate intensity exercise daily [2].

At the end of one week each participant attended for review with a clinical facilitator (nurse or physiotherapist) who had been involved in supervising the CR programmes and who recorded the previous 7 days' step-counts from their pedometer. Following this, their allocation to intervention or control treatments was revealed by the facilitator. $\mathrm{CR}$ programme group allocations were pre-determined at the outset of the study using a quasi-random method, alternating the treatment for successive groups and allocating two groups to each condition. Randomisation was not conducted at the level of individuals in order to avoid contamination effects which may have resulted from personal interactions between patients who established friendships during their CR: all patients in the same CR programme group were allocated to the same study group. The intervention groups began the study in May and October; the controls began in July and December.

Intervention groups, based on a previous community-based study of rehabilitation for patients with back pain [13] were asked to wear the pedometer, record daily step-counts in a diary and meet a facilitator weekly to review their progress. At each meeting the facilitator checked diary records against pedometer memory values and helped individuals to set realistic step-count goals for the following week, encouraging a gradual $10 \%$ increase in average daily count, aiming for 10,000 steps/ day.

For the control groups, the facilitator recorded baseline pedometer data but gave no feedback information regarding their step-counts to participants. They continued weekly contact with the facilitator, either face-to-face or by telephone, as preferred, to allow them access to ongoing clinical support and discuss their progress.

During week 6 both groups were asked to wear a pedometer again, blinded to step-count records. Following this, feedback was given to all participants.

At the outset and at their final visit, participants self-completed a 'stages of change' questionnaire for PA [14] and a validated quality of life questionnaire (EQ5D) [15]. At the end of the study an independent researcher, previously unknown to participants, conducted semistructured interviews with all participants, exploring their reasons for participating and views on their experience of it. Interviews were audio-recorded, transcribed anonymously and analysed using a thematic framework.

\section{Statistical analysis}

A valid day of measurement was defined as $>300$ steps. Any daily reading of less than 300 steps was discarded, as this was considered to indicate that the device was not worn and its inclusion would lead to a significant underestimation of steps per day. Following this, mean steps/day was calculated for each week. Using SPSS v19, differences between groups were examined using one-way ANOVA for parametric data and Kruskal Wallis testing for nonparametric data. Difference in mean age was analysed using an independent t-test, after checking for normality of distribution. Analysis of covariance was used to test differences between groups in changes from baseline, using cohort as a covariate to account for possible cluster effects. An intra-cluster correlation co-efficient calculation was made for step-count outcomes, based on the extent of change within each study group.

\section{Results}

Of the 68 patients invited, $45(66 \%)$ participated. Two CR programme groups received the intervention; 2 were controls. Reasons for non-participation were similar for all groups and included time (6), distance (3), work (5), disinterest (5) and co-morbidity (4). Most participants completed the study and all outcome measures $(90 \%$ (17/19) intervention; 96\% (25/26) control). Three participants failed to complete the study ( 1 control, influenza; 2 intervention: anaemia, depression). At baseline, there were no statistically significant differences between the groups (Table 1). The majority of participants were male $(41 / 45 ; 91 \%)$; the mean age of participants in the intervention groups was 61.6 years (SD 11.3) and in the control groups was 59.2 years (SD 8.9) $(\mathrm{p}=0.43)$. Approximately $80 \%$ were in the 'active' or 'maintenance' stage of change in PA behaviour. Overall, approximately one third (35.6\%) had been categorised [12] as high risk at the outset of their CR programme.

The intervention groups increased their steps/day significantly more than controls (Table 2) (mean increase 2,742 (SD 3,164) v -42 (SD 2,624)). This difference remained significant after taking account of baseline data. None of the participants in either group engaged in water-based activities during the study measurement periods. For the intervention group, the greatest increase in steps occurred in the first week of the intervention, with more gradual and sustained increase thereafter (Figure 1). They achieved a mean of 8,352 steps/day (SD 2602; range 2317-12390). No significant differences were observed between groups in change in quality of life or stage of behaviour change

\begin{tabular}{|l|c|c|c|}
\hline & Intervention (N=19) & Control (N=26) & \\
\hline Gender & $\mathbf{N}(\%)$ & $\mathbf{N}(\mathbf{\%})$ & *p-value \\
\hline Male & & & 0.17 \\
\hline Female & $16(84.2 \%)$ & $25(96.2 \%)$ & \\
\hline BACR risk & $3(15.8 \%)$ & $1(3.8 \%)$ & \\
\hline Low & $1(5.3 \%)$ & $1(4.2 \%)$ & 0.86 \\
\hline Moderate & $11(57.9 \%)$ & $16(61.5 \%)$ & \\
\hline High & $7(36.8 \%)$ & $9(34.6 \%)$ & \\
\hline Stage of Change & & & 0.41 \\
\hline Pre-Contemplation & $0(0.0 \%)$ & $1(3.8 \%)$ & \\
\hline Contemplation & $4(21.1 \%)$ & $1(3.8 \%)$ & \\
\hline Preparation & $0(0.0 \%)$ & $1(3.8 \%)$ & \\
\hline Action & $8(42.1 \%)$ & $11(42.3 \%)$ & \\
\hline Maintenance & $7(36.8 \%)$ & $12(46.2 \%)$ & \\
\hline
\end{tabular}

${ }^{*}$ Chi square analysis for gender; Kruskal Wallis testing for differences in othe variables between groups

Table 1: Comparison of Groups at Baseline. 
Citation: Cupples M, Dean A, Tully MA, Taggart M, McCorkell G, et al. (2013) Using Pedometer Step-Count Goals to Promote Physical Activity in Cardiac Rehabilitation: A Feasibility Study of a Controlled Trial. Int J Phys Med Rehabil 1: 157. doi:10.4172/2329-9096.1000157

Page 3 of 5

(Table 2). Comparing the variation in step-counts recorded in each of the 4 groups we found an intra-cluster correlation co-efficient (ICC) of 0.24 , at a significance level of 0.05 , with $80 \%$ power.

Completion of pedometer measurement recordings was high: of a possible total of 35 days, intervention participants recorded valid step-counts on a mean of 30 days (SD 6, range 16-35). A measure of adherence to the intervention programme was calculated for each individual, based on the number of their valid days of measurement on which they achieved their weekly step-count goal, and expressed as a percentage. Overall, the mean percentage of days on which individuals achieved their goal was $62.3 \%$ (SD $18.7 \%$; range $28.6 \%$ to $91.4 \%$ ).

Reasons that prevented adherence to goals included holidays, stent insertion, ankle injury, knee and back pain, low mood and inclement weather. One participant reported shortness of breath and another, a soft tissue knee injury: both completed the study.

\section{Reasons for participating}

All 45 participants took part in a one-to-one semi-structured interview. Most stated that reasons for participating in the study related to their health and a wish to do whatever was possible to maintain,

\begin{tabular}{|l|l|l|l|l|l|l|l|}
\hline & \multicolumn{3}{|c|}{ Intervention (n=19) } & \multicolumn{3}{c|}{ Control (n=26) } & \\
\hline & Mean & SD & $\mathbf{9 5 \%}$ Cl & Mean & SD & $\mathbf{9 5 \%}$ Cl & p-value \\
\hline $\begin{array}{l}\text { Baseline Steps/ } \\
\text { day }\end{array}$ & 6,123 & 3,151 & $4,605-7,642$ & 7,869 & 4,209 & $6,169-9,569$ & $0.14^{*}$ \\
\hline $\begin{array}{l}\text { Baseline EQ5D } \\
\text { Health Status } \\
\text { (0-100) }\end{array}$ & 67.11 & 22.70 & $56.17-78.05$ & 72.73 & 16.10 & $66.23-79.23$ & $0.34^{*}$ \\
\hline $\begin{array}{l}\text { Baseline EQ5D } \\
\text { Health index }\end{array}$ & 6.2105 & 1.84 & $5.32-7.10$ & 6.46 & 1.92 & $5.68-7.24$ & $0.66^{*}$ \\
\hline $\begin{array}{l}\text { Change in steps/ } \\
\text { day }\end{array}$ & 2,742 & 3,164 & $1,169-4,316$ & -42 & 2,624 & $-1,102-1,018$ & $0.004^{* *}$ \\
\hline $\begin{array}{l}\text { Change in EQ5D } \\
\text { Health Status } \\
\text { (0-100) }\end{array}$ & 6.16 & 13.24 & $-0.22-12.54$ & 2.54 & 12.45 & $-2.49-7.57$ & $0.65^{\star *}$ \\
\hline $\begin{array}{l}\text { Change in EQ5D } \\
\text { Health index }\end{array}$ & 0.05 & 0.71 & $-0.29-0.39$ & -0.19 & 1.41 & $-0.76-0.38$ & $0.75^{\star *}$ \\
\hline
\end{tabular}

*One-way ANOVA for differences between groups at baseline

** One-way ANCOVA with cohort as a covariate

Table 2: Comparison between groups of mean daily step counts and quality of life measures (EQ5D) at baseline and extent of change within groups during study.

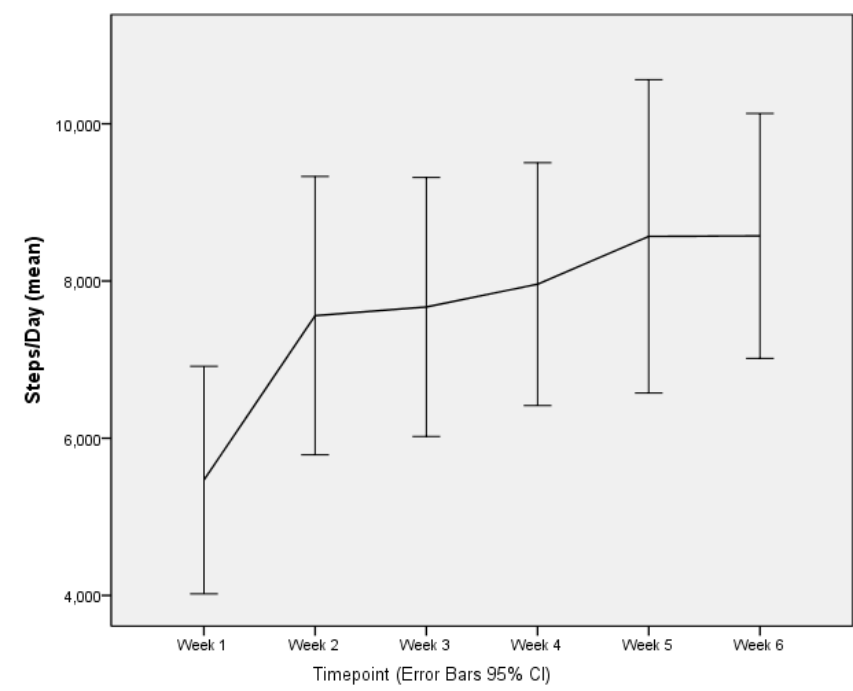

Figure 1: Change in weekly physical activity over time (Intervention Group). monitor or improve their well-being. One simply said: "I want to be healthy" (57 year old male, control). Many wanted to contribute to the body of knowledge about how best to treat others who had or were at risk of having heart disease. For example, ".... if it can help me, then it can help my son too" (54 year old male, intervention). Others participated because they wished to show appreciation for the care they had received during their recovery from their cardiac event: ".... the people were taking an interest in my health, so to repay them" (39 year old female, intervention). Participants also valued having ongoing contact with clinical staff: "you always felt that there was somebody still there worrying about you.......... there was somebody interested" (50 year old male, control). They recognised a lack of follow-up opportunities to encourage maintenance of healthy lifestyles, including PA: "There is no sort of outreach whatever when the (CR) programme is finished" (50 year old male, intervention).

\section{Impact on physical activity}

All intervention group participants perceived that the intervention had a positive impact on their physical activity. Some, who previously took 30 minutes of PA most days, based on recommendations given to them during their formal CR programme, became more aware of their actual level of PA. They identified that the step-counts helped them increase PA: "It encouraged me to walk every day and I started at 5,000 (steps) and now I have finished up at 8,500" (40 year old male). Having a target step-count encouraged patients to leave the safety of their homes: "It's made me go out because I know I've got to do those 10,000 steps, I'm not going to do them just sitting round the house" (55 year old female). Their experience of taking part in the study also helped increase their confidence in doing physical activity: "now I know what I can do and what my limitations are" (40 year old female). Some comments suggested that participants regarded the pedometer as a companion who motivated them to be more active: "It would push me more ......I'm aware that you know this (pedometer) is on and I have to get her going you know!" (58 year old male) Other comments indicated plans for the continued use of a pedometer to maintain their motivation to be physically active: "It's a good guide and .... will give me the incentive and keep things ticking over" (51 year old male).

\section{Experience of intervention}

Participants' experiences of pedometers were mainly positive: "no problem, just clipped it on my belt and away I went" (74 year old male). Five reported that their pedometer was under-recording (one stated "..... getting a very low reading, even though I knew that I had done a good amount of steps" (62 year old male)). Other problems included opening the pedometer cover $(n=1)$, re-setting it $(n=2)$, discomfort $(n=2)$ and difficulty attaching it to clothing $(n=2)$. Problems were resolved by repositioning the pedometer and providing practical advice.

\section{Discussion}

These findings indicate that a randomised controlled trial of a tailored intervention, setting step-count goals, is feasible in the context of clinical practice and of potential value to help cardiac rehabilitation patients to increase their engagement in PA. A majority of patients who had completed a supervised hospital-based rehabilitation programme agreed to participate; they showed high rates of adherence to the intervention and of completion of outcome measures. Participants perceived that step-count goals were more effective in promoting PA than were time-related targets. Objectively measured goals with immediate feedback, such as pedometer step-counts, appear to help patients to translate recommendations, based on duration and intensity 
of PA, into practice and clinical staff should be aware of potential problems and solutions regarding pedometer use.

The intervention group participants achieved a mean step-count of 8352 steps/day, with a mean increase of 2,742 steps/day. An increase of at least 2,500 steps/day is associated with health benefits for people with chronic conditions [10]. The extent of change which we have observed is likely to be of clinical significance for patients with heart disease. Indeed, it has been shown that accumulating 6,500-8,500 steps/day may arrest or reverse coronary artery lesion progression [16]. Whilst 10,000 steps/day and above have been recommended for the achievement of health benefits for healthy adults, adults with chronic illness typically accumulate lower levels of PA [10].

The reasons reported by our participants for their inability to meet their step-count goals concurred with those of Goodrich et al. [17] who reported that $87 \%$ of adverse events in a walking programme for high risk individuals were issues that were likely to occur among older people, even unrelated to walking. Our participants all had completed a CR programme in a supervised setting. They included several who were categorised as 'high risk' but these patients, and others with comorbidities that may have affected their ability to be physically active, had been appropriately monitored and advised during exercise within $\mathrm{CR}$ sessions. We consider that this gave them confidence to participate in unsupervised PA within the community and contributed to the low levels of reported inability to adhere to the walking goals.

Sustaining moderate levels of PA is important in maintaining health benefits [3]. Previous reports have indicated that interventions which are most effective in promoting PA among cardiac patients include prompt self-monitoring and specific goal setting [4], but reports of pedometer-based interventions have included little methodological detail of how the pedometers were actually used [5-8]. Other work has reported that patients who engaged in some form of PA at home were more active than those who only engaged in exercise during CR sessions [18] but only $8 \%$ of that study's participants reached the recommended minimum level of weekly PA. It was concluded that patients should be strongly encouraged to increase their volume of PA. Clarke et al. [19] reported how little support to maintain the desired levels of PA was available for patients in the community after a relatively short period of formal CR: peer support groups have the potential to provide support but only $35 \%$ of patients (79/225) participated in these., The use of a pedometer, together with a socio-cognitive intervention, was considered to be effective in increasing PA for patients with acute coronary syndrome for up to a year after their event [20]. Our report regarding patients' use of pedometers and tailored goal-setting provides new detail on how pedometers may be used to provide encouragement which is acceptable to a majority of patients.

Our results indicate that a definitive randomised controlled trial (RCT) is feasible. Using the ICC which we derived from our results and the equation of Bennet and Hayes [21] we estimated that, for a fully powered cluster RCT, to detect a change of 2742 steps in the intervention group, with no change in the control group and with $80 \%$ power and a significance level of 0.05 , a total of 6 clusters ( 3 intervention; 3 control) of 11 participants per cluster would be required. We recognise that trial designs in which individuals are randomised, rather than clusters, require smaller samples to determine statistically significant differences, but consider that a cluster design allows better implementation of the intervention to be tested in practice, with less risk of contamination by unplanned interactions between study participants.

\section{Strengths and limitations}

Our study's strengths include the relatively high participation rate
(66\% of invitees) and low drop-out rate: only 3 of our 45 participants (6.7\%) failed to complete the study. The study groups were well balanced regarding their baseline characteristics and the quasi-experimental cluster randomised design prevented contamination of intervention effect through friendships within established CR programme groups. Bias in baseline measurements was minimised by blinding participants to their pedometer step-count readings and by only revealing their treatment allocation to them after baseline measurements were completed. The method used to clean the data, by discarding very low step-count readings, is a recognised and validated procedure.

The interviews identified that adherence to the intervention protocol was supported by patients' appreciation of their opportunity to have ongoing clinical contact: integration of hospital staff with other clinical staff in the wider community and continuing support for patients should be considered when designing interventions to sustain PA [19]. However, whilst control group participants also appreciated staff contact, their failure to increase PA supports the view that objective measures using pedometers, and feedback regarding achievements, have value.

It is acknowledged that the study was undertaken in a single setting and that good relationships established previously with the clinical staff who conducted the research, may mean that participants were more motivated than a wider eligible population and thus limit the generalisability of the findings. However, it appears feasible and worthwhile to conduct a definitive randomised controlled trial of this intervention in a multicentre study and settings where personal knowledge may not be a confounding factor. The generalisability of findings is also limited as the socio-economic or occupational status of participants is not known: more detailed demographic data should be recorded in a definitive study.

\section{Conclusion}

A progressive, tailored programme using step-counts as goals is feasible in clinical practice for patients who have completed a formal CR programme. Staff awareness of practical information about the appropriate positioning and use of pedometers is important. A randomised controlled trial which includes a range of settings, longer follow-up and measures of duration and intensity of PA would be valuable in determining the effectiveness and sustainability of this intervention for patients in ongoing rehabilitation.

\section{Acknowledgements}

We wish to thank the Northern Ireland Chest Heart Stroke Association and the Research and Development Office of the Western Health and Social Care Trust, Northern Ireland for funding and supporting this work. (NICHS Grant Number 200936; WHSCT Project Ref; WT08/63) Professor Cupples is part-funded by the UKCRC Centre of Excellence for Public Health Research (NI): funding from the British Heart Foundation, Cancer Research UK, Economic and Social Research Council, Medical Research Council, Research and Development Office for the Northern Ireland Health and Social Services and the Wellcome Trust, under the auspices of the UK Clinical Research Collaboration, is gratefully acknowledged.

\section{References}

1. Lee IM, Shiroma EJ, Lobelo F, Puska P, Blair SN, et al. (2012) Effect of physica inactivity on major non-communicable diseases worldwide: an analysis of burden of disease and life expectancy. Lancet 380: 219-229.

2. Perk J, De Backer G, Gohlke H, Graham I, Reiner Z, et al. (2012) European Guidelines on cardiovascular disease prevention in clinical practice (version 2012). The Fifth Joint Task Force of the European Society of Cardiology and Other Societies on Cardiovascular Disease Prevention in Clinical Practice (constituted by representatives of nine societies and by invited experts). Eur Heart J 33: 1635-1701.

3. Chase JA (2011) Systematic review of physical activity intervention studies after cardiac rehabilitation. J Cardiovasc Nurs 26: 351-358. 
Citation: Cupples M, Dean A, Tully MA, Taggart M, McCorkell G, et al. (2013) Using Pedometer Step-Count Goals to Promote Physical Activity in Cardiac Rehabilitation: A Feasibility Study of a Controlled Trial. Int J Phys Med Rehabil 1: 157. doi:10.4172/2329-9096.1000157

Page 5 of 5

4. Ferrier S, Blanchard CM, Vallis M, Giacomantonio N (2011) Behavioura interventions to increase the physical activity of cardiac patients: a review. Eur $\mathrm{J}$ Cardiovasc Prev Rehabil 18: 15-32.

5. Kazuhiro I, Satoshi W, Kazuto O, Hirano Y, Oka k, et al. (2005) Effect of the SelfMonitoring Approach on Exercise Maintenance During Cardiac Rehabilitation: A Randomized, Controlled Trial. Am J Phys Med Rehabil 84: 313-321.

6. Butler L, Furber S, Phongsavan P, Mark A, Bauman A (2009) Effects of a pedometer-based intervention on physical activity levels after cardiac rehabilitation: a randomized controlled trial. J Cardiopulm Rehabil Prev 29 : 105-114.

7. Pinto BM, Goldstein MG, Papandonatos GD, Farrell N, Tilkemeier P, et al. (2011) Maintenance of exercise after phase II cardiac rehabilitation: a randomized controlled trial. Am J Prev Med 41: 274-283.

8. Furber S, Butler L, Phongsavan P, Mark A, Bauman A (2010) Randomised controlled trial of a pedometer-based telephone intervention to increase physical activity among cardiac patients not attending cardiac rehabilitation. Patient Educ Couns 80: 212-218.

9. Bravata DM, Smith-Spangler C, Sundaram V, Gienger AL, Lin N, et al. (2007) Using pedometers to increase physical activity and improve health: a systematic review. JAMA 298: 2296-2304.

10. Tudor-Locke C, Craig CL, Aoyagi Y, Bell RC, Croteau KA, et al. (2011) How many steps/day are enough? For older adults and special populations. Int J Behav Nutr Phys Act 8: 80 .

11. National Institute for Health and Clinical Excellence (2006) PH2 Four commonly used methods to increase physical activity: guidance.

12. British Association for Cardiovascular Prevention and Rehabilitation (2012) The BACPR Standards and Core Components for Cardiovascular Disease Prevention and Rehabilitation. ( $2^{\text {nd }}$ Edn), BACPR, London.
13. McDonough SM, Tully MA, O'Connor SR, Boyd A, Kerr DP, et al. (2010) The back 2 activity trial: education and advice versus education and advice plus a structured walking programme for chronic low back pain. BMC Musculoskelet Disord 11: 163.

14. Marcus BH, Rossi JS, Selby VC, Niaura RS, Abrams DB (1992) The stage and processes of exercise adoption and maintenance in a worksite sample. Health Psychol 11: 386-395.

15. Ellis JJ, Eagle KA, Kline-Rogers EM, Erickson SR (2005) Validation of the EQ$5 \mathrm{D}$ in patients with a history of acute coronary syndrome. Curr Med Res Opin 21: 209-216.

16. Ayabe M, Brubaker PH, Dobrosielski D, Miller HS, Kiyonaga A, et al. (2008) Target step count for the secondary prevention of cardiovascular disease. Circ J 72: 299-303.

17. Goodrich DE, Larkin AR, Lowery JC, Holleman RG, Richardson CR (2007) Adverse events among high-risk participants in a home-based walking study: a descriptive study. Int J Behav Nutr Phys Act 4: 20.

18. Jones NL, Schneider PL, Kaminsky LA, Riggin K, Taylor AM (2007) An assessment of the total amount of physical activity of patients participating in a phase III cardiac rehabilitation program. J Cardiopulm Rehabil Prev 27: 81-85.

19. Clark AM, Mundy C, Catto S, MacIntyre PD (2011) Participation in community based exercise maintenance programs after completion of hospital-based cardiac rehabilitation: a mixed-method study. J Cardiopulm Rehabil Prev 31 : $42-46$.

20. Houle J, Doyon O, Vadeboncoeur N, Turbide G, Diaz A, et al. (2012 Effectiveness of a pedometer-based program using a socio-cognitive intervention on physical activity and quality of life in a setting of cardiac rehabilitation. Can J Cardiol 28: 27-32.

21. Hayes RJ, Bennett S (1999) Simple sample size calculation for clusterrandomized trials. Int J Epidemiol 28: 319-326.
Citation: Cupples M, Dean A, Tully MA, Taggart M, McCorkell G, et al. (2013) Using Pedometer Step-Count Goals to Promote Physical Activity in Cardiac Rehabilitation: A Feasibility Study of a Controlled Trial. Int J Phys Med Rehabil 1: 157. doi:10.4172/2329-9096.1000157
Submit your next manuscript and get advantages of OMICS Group submissions

Unique features:

- User friendly/feasible website-translation of your paper to 50 world's leading languages

Audio Version of published paper

Digital articles to share and explore

Special features:

250 Open Access Journals

20,000 editorial team

21 days rapid review process

Quality and quick editorial, review and publication processing

- Indexing at PubMed (partial), Scopus, EBSCO, Index Copernicus and Google Scholar etc

- Sharing Option: Social Networking Enabled

- Authors, Reviewers and Editors rewarded with online Scientific Credits

- Befter discount for your subsequent articles

Submit your manuscript at: http://www.omicsonline.org/submission/ 